\section{Evolução do acesso à água fluoretada no Estado de São Paulo, Brasil: dos anos 1950 à primeira década do século XXI}

\author{
Evolution in access to fluoridated water in São \\ Paulo State, Brazil, from the 1950s to the \\ early 21 st century
}

\author{
Renata Ximenez Alves 1 \\ Grasiele Fretta Fernandes 1 \\ Maria Tereza Pepe Razzolini 1 \\ Paulo Frazão ${ }^{1}$ \\ Regina Auxiliadora de Amorim Marques 1 \\ Paulo Capel Narvai 1
}

\author{
${ }^{1}$ Faculdade de Saúde \\ Pública, Universidade de São \\ Paulo, São Paulo, Brasil. \\ Correspondência \\ R.X. Alves \\ Centro Colaborador do \\ Ministério da Saúde em \\ Vigilância da Saúde Bucal, \\ Faculdade de Saúde Pública, \\ Universidade de São Paulo. \\ Av. Dr. Arnaldo 715, São Paulo, \\ SP 01246-904, Brasil. \\ reximenez@usp.br
}

\section{Abstract}

Access to fluoridated water is a known protective factor against dental caries. In 1974, fluoridation of the public water supply became mandatory by law in Brazil, resulting in improved coverage, especially in more developed regions of the country. Coverage increased across the country as a priority under the national oral health policy. This article systematizes information on the implementation and expansion of fluoridation in Sao Paulo State from 1956 to 2009, using secondary data from technical reports, official documents, and the Information System for Surveillance of Water Quality for Human Consumption (SISAGUA). In 2009, fluoridation covered 546 of 645 counties in São Paulo State (84.7\%), reaching $85.1 \%$ of the total population and $93.5 \%$ of the population with access to the public water supply. The results indicate that fluoridation has been consolidated as part of State health policy. However, the challenge remains to implement and maintain fluoridation in 99 counties, benefiting 6.2 million inhabitants that are still excluded from this service.

Fluoridation; Water Supply; Oral Health

\section{Introdução}

A cárie dentária representa, em termos de saúde bucal, o principal agravo em saúde pública no Brasil, atingindo, ainda que de modo desigual, indivíduos de todas as faixas etárias e níveis socioeconômicos 1 .

O uso do flúor em saúde pública, sob a forma de fluoreto, é considerado o principal fator de proteção, decisivo para a obtenção de expressiva redução na prevalência da doença. Em geral, os principais meios utilizados nas estratégias populacionais de uso de fluoretos para prevenir a cárie são o creme dental e a água de abastecimento público 2,3 .

O Centers for Disease Control and Prevention (CDC), dos Estados Unidos, define fluoretação da água como sendo a adição deliberada do elemento natural flúor na água de abastecimento público, em conformidade com os padrões técnicos e recomendações científicas ${ }^{4}$. Assim, a fluoretação da água se constitui numa tecnologia de saúde pública, cujo emprego requer, além de recursos, o conhecimento e o controle da situação em que é utilizada.

Trata-se de uma medida eficaz e segura, consagrada mundialmente, recomendada pelas entidades odontológicas, dentre as quais a American Dental Association (ADA), que a fez pela primeira vez em 1950, e pela Organização Mundial da Saúde (OMS), em 1966. Em 2007, em sua 60a 
Assembléia Mundial de Saúde, a OMS reiterou a recomendação 5,6 .

Essa tecnologia vem sendo utilizada, em todo o mundo, há mais de seis décadas, sendo considerada pelo CDC como uma das 10 maiores conquistas de saúde pública no século $\mathrm{XX}$, nos Estados Unidos. Estima-se que seu poder preventivo esteja em torno de $40 \%$ a $70 \%$ em crianças, além de reduzir a perda dentária em adultos de $40 \%$ a $60 \%$ 7,8. O benefício da água fluoretada é extensivo a todos, em todas as idades. Contudo, a força preventiva da medida é maior nos grupos mais vulneráveis ao agravo 9,10. Para Narvai 11, os principais interessados na fluoretação das águas de abastecimento público são os segmentos sociais de baixa renda, pois estes são os mais vulneráveis à cárie dentária quando não se faz ou se interrompe a fluoretação. No Brasil, a medida é regulamentada por meio da Lei Federal $n^{\circ}$. 6.050, de 1974 12, e do Decreto Federal no. 76.872, de 1975 13, que dispõem sobre a obrigatoriedade da fluoretação em todos os sistemas de tratamento de água de abastecimento público.

Embora a medida seja aplicada no Brasil desde 1953, a cobertura da fluoretação nos municípios tem sido pouco documentada, tornando obscuro o conhecimento sobre o acesso ao benefício nas diversas localidades do território brasileiro, mesmo sendo a ampliação deste acesso uma das prioridades da política nacional de saúde bucal 14 .

Dados do levantamento de saúde bucal realizado no Brasil em 2003 15, revelam que 115 (46\%) dos 250 municípios avaliados proporcionavam acesso à água fluoretada. As regiões Sudeste e Sul eram as que estavam em melhor situação quanto à cobertura, com $66 \%$ e $88 \%$, respectivamente.

Neste artigo, aborda-se a problemática do acesso à água fluoretada no âmbito do Estado de São Paulo, analisando-se a expansão da cobertura da medida, desde a sua implantação em 1956, até o final da primeira década do século XXI. Com isso, busca-se contribuir para melhorar o conhecimento do assunto no Estado de São Paulo e, deste modo, ampliar e estimular a sistematização de conhecimentos sobre a fluoretação das águas em todo o Brasil.

\section{Material e método}

A escolha do início do período definido para este estudo decorreu do fato da fluoretação das águas de abastecimento público ter-se iniciado, no Estado de São Paulo, em 1956, no Município de Marília 16. Segundo Narvai 11, 12 de dezembro representa, portanto, a data de introdução dessa tecnologia no estado.
Com população de 41.633.802 habitantes em 2009, São Paulo possui 645 municípios e constitui a Unidade da Federação mais populosa, com quase $22 \%$ da população brasileira (Fundação Seade. http://www.seade.gov.br, acessado em 03/Abr/2010). Segundo o Instituto Brasileiro de Geografia e Estatística (IBGE) 17, em 2000, a água de abastecimento público chegava a $100 \%$ dos municípios.

Neste estudo, foram utilizados dados secundários, provenientes de documentos variados, relatórios oficiais e publicações científicas. O material bibliográfico foi obtido por meio de busca sistematizada nas Bases de Dados disponibilizadas no portal da Biblioteca Virtual em Saúde (BVS). As palavras-chave foram: "fluoretação-estado", "fluoretação-cidade”, "fluoretaçãomunicípio" e "cobertura-fluoretação", sendo selecionadas as publicações pertinentes para o período 1956-2009.

Também foi consultado o Sistema de Informação de Vigilância da Qualidade da Água para Consumo Humano (SISAGUA) 18, mantido pelo Ministério da Saúde. O acesso ao SISAGUA foi autorizado pelo gestor federal do sistema.

As variáveis consideradas para este estudo foram:

a) Município: foram considerados os municípios existentes no período, cujo número variou de 435, em 1956, a 645 em 2009;

b) População total do município: obtida no portal da Fundação Seade;

c) População total do estado: obtida por meio do portal da Fundação Seade;

d) População com acesso à água tratada no município: identificada pelo acesso urbano à rede geral de abastecimento de água, obtida nos anos de 1991 e 2000, junto à Fundação Seade;

e) População com acesso à água tratada no estado: corresponde à soma das populações com acesso à água tratada em cada município, obtida para os anos de 1991 e 2000, junto à Fundação Seade, e pelos dados de cobertura de redes de abastecimento de água junto à Pesquisa Nacional por Amostra de Domicílios (PNAD, 2007) na base de dados "Indicadores e Dados Básicos Brasil - 2008” (http://tabnet.datasus.gov.br/cgi/ idb2008/matriz.htm, acessado em 03/Dez/2008), a partir de 1980;

f) Presença de fluoretação no sistema de abastecimento público de água: os dados registrados para esta variável tiveram origem em fontes documentais oficiais ou na literatura científica, situação em que o município constava como "sim" ou "fluoretado". No caso das fontes documentais oficiais, adotou-se como regra de decisão para a condição "Presença de fluoretação" que o município deveria apresentar, no período de um 
ano, menos do que $50 \%$ de amostras com níveis abaixo de 0,6mg/L de fluoreto. Para lidar com situações em que havia indício de fluoretação, detectado por meio de amostras coletadas com certa periodicidade, mas a medida não atendia aos padrões definidos para se considerar a fluoretação consolidada, construiu-se um indicador com base no percentual de amostras com teores de flúor menores do que 0,6mg/L. Buscou-se, desse modo, detectar e mensurar o grau de hipofluoretação, equivalente, para todos os fins, à ausência da fluoretação no município, tendo em vista o teor mínimo de flúor preconizado pelo Estado de São Paulo 19. Tal indicador recebeu o nome de Indicador de Hipofluoretação (IHF) e foi calculado com o emprego da seguinte fórmula:

$$
\mathrm{IHF}=\frac{\begin{array}{c}
\text { número de amostras } \\
\text { com teor de flúor }<0,6
\end{array}}{\text { número total de amostras }} \times 100
$$

Assim, para cada município: Se IHF $\leq 50 \%$ = Município com fluoretação Se IHF $>50 \%=$ Município sem fluoretação

A definição de cobertura, utilizada neste estudo como indicador de acesso, foi: percentual da população residente servida por rede geral de abastecimento, com fluoretação como etapa de tratamento, com ou sem canalização domiciliar, em determinado espaço geográfico, no ano analisado (adaptado do IBGE) 17. Considerou-se um município fluoretado quando este possuía pelo menos um sistema de tratamento com fluoretação, no ano sob estudo (http://tabnet.datasus. gov.br/cgi/idb2008/matriz.htm, acessado em 03/Dez/2008).

Para subsidiar a discussão sobre a evolução do acesso à medida no estado, foram construídos indicadores sobre a cobertura de fluoretação da água de abastecimento público, os quais são apresentados por meio de gráficos e mapas temáticos. Convencionou-se que o penúltimo ano da década foi o escolhido para os cálculos, encerrando cada período em estudo. Assim, o recorte foi feito nos anos de final 9 (nove).

As categorias de análise estão a seguir:

a) População total: percentual da população com fluoretação presente, residente no Estado de São Paulo, nos anos considerados;

$$
\% \text { de população total }=\frac{\begin{array}{c}
\text { população com } \\
\text { acesso à água } \\
\text { fluoretada } \text { no estado, } \\
\text { no ano } X
\end{array}}{\begin{array}{c}
\text { população total do } \\
\text { estado } \text { no } \text { ano } X
\end{array}} \times 100
$$

b) Percentual da população abastecida por rede geral de abastecimento de água que recebe água fluoretada, no Estado de São Paulo, no ano considerado;

$$
\begin{aligned}
& \text { população com } \\
& \text { acesso à água }
\end{aligned}
$$

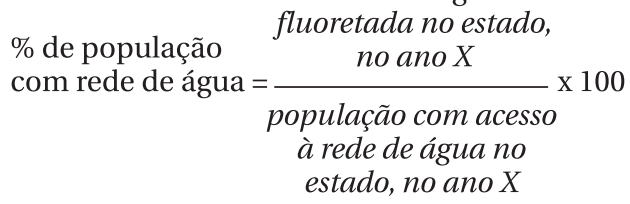

A população com acesso à água fluoretada no município foi obtida pela população com acesso à rede de abastecimento de água nos municípios com fluoretação, nos anos considerados. A população com acesso a água fluoretada no estado foi obtida pela soma da população com acesso à água de todos os municípios com fluoretação do estado;

c) Número de municípios que interromperam a fluoretação: corresponde à diferença entre o número de municípios com data de início da fluoretação relatada até o início do período e o número de municípios com fluoretação presente no mesmo período. Para o cálculo, utilizou-se o número de municípios com início de fluoretação de 1956 a 1988. O número de municípios detectados como "fluoretados" nos anos a seguir, até 2009, foi considerado "sem interrupção" da fluoretação. O número de municípios detectados como "não fluoretados" em pelo menos um ano, de 1988 a 2009, foi considerado "com interrupção" da fluoretação.

Os mapas temáticos são apresentados de acordo com a data de início da fluoretação para os decênios 1950, 1960, 1970, 1980, 1990 e 2000, estabelecidos como: (i) anos 1950: período de 1950 a 1959; (ii) anos 1960: período de 1960 a 1969; (iii) anos 1970: período de 1970 a 1979; (iv) anos 1980: período de 1980 a 1989; (v) anos 1990: período de 1990 a 1999; e (vi) anos 2000: período de 2000 a 2009.

Os mapas sobre cobertura da fluoretação representam o número de municípios que realizavam a fluoretação nos anos de 1989, 1999 e 2009.

Os mapas foram produzidos com base nos sistemas de informações geográficas, com o uso do programa de geoprocessamento TerraView Política Social, versão 3.3.1, do Instituto Nacional de Pesquisas Espaciais (INPE; http://www.dpi. inpe.br/terraview) e da malha municipal digital 2005 do Estado de São Paulo, oficializada pelo IBGE (http://www.ibge.gov.br/home/geociên cias/default_prod.shtm\#TERRIT, acessado em 25/Mar/2010), com escala de referência da base de $1: 2.500 .000$. 


\section{Resultados}

A cobertura da fluoretação no Estado de São Paulo evoluiu de apenas um para 546 municípios, no período de estudo. Em 2009, não contavam com a medida 99 municípios. Nesse ano, São Paulo apresentava $85,1 \%$ da população total com acesso à água fluoretada. Considerando-se a fração da população com acesso à rede de distribuição de água, 93,5\% tinham acesso à água fluoretada. Dentre os municípios sem a medida, 99\% tinham menos de 50 mil habitantes.

No Brasil, segundo dados oficiais, em 1996 a cobertura de água fluoretada teria atingido $42 \%$ da população. No ano 2000, 97,9\% dos municípios contavam com abastecimento de água, mas apenas $45 \%$ destes adicionavam flúor em seus sistemas de abastecimento público. No Estado de São Paulo, a água de abastecimento público chegava a $100 \%$ dos municípios, enquanto a água fluoretada chegava a 449 municípios paulistas.

Foram localizados dois estudos sobre acesso à água fluoretada no Estado de São Paulo, com especificação da situação por município. Um desses estudos 20 refere que, em 1983, o número de municípios fluoretados era de 145, representando 25\% dos municípios do estado. Naquele ano, apenas $26 \%$ da população paulista tinha acesso ao benefício. O outro estudo 21 mostrou que, após 14 anos, esse percentual havia se elevado para $79 \%$, sendo que $61 \%$ dos municípios eram beneficiados pela medida.

A Figura 1 mostra a evolução da população total coberta por fluoretação da água de abastecimento público no Brasil e no Estado de São Paulo, no período de 1950 a 2000.

Os mapas temáticos apresentados na Figura 2 mostram a data de início da fluoretação da água de abastecimento público nos municípios do Estado de São Paulo, de acordo com os decênios previamente estabelecidos.

Em 2009, 93,5\% da população abastecida por água contavam com a medida. A Figura 3 mostra a evolução da proporção da população abastecida por rede de água servida por água fluoretada, no Estado de São Paulo, no período de 1972 a 2009.

Sobre a interrupção da fluoretação, a Figura 4 mostra a comparação entre os mapas que

Figura 1

Porcentagem da população total com acesso à água de abastecimento público fluoretada, no Brasil e no Estado de São Paulo, no período de 1950 a 2000.

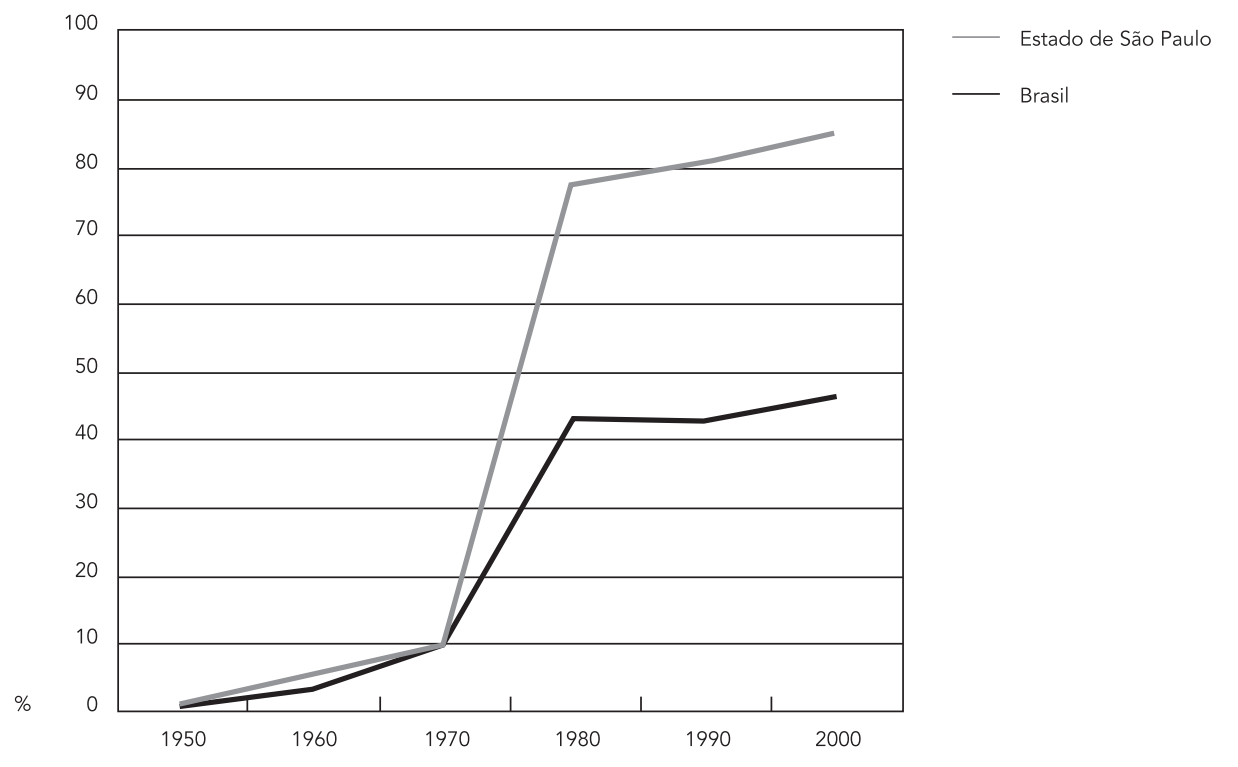

Fonte: Secretaria de Atenção à Saúde, Ministério da Saúde 15, Buendia 20, Narvai 37, Organización Panamericana de la Salud 38 , Grinplastch 39, Batalha et al. 40, Grupo Estadual de Controle e Fluoretação das Águas 41, Silva 42, Programa de Vigilância da Qualidade da Água para Consumo Humano do Estado de São Paulo 43 e Fundação Seade (http://www.seade.gov.br, acessado em 03/Abr/2010). 
2a) Anos 1950

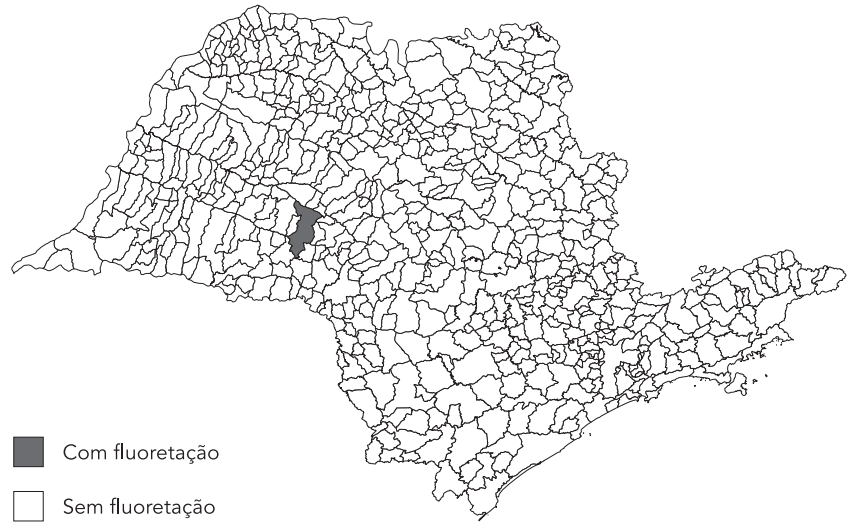

2c) Anos 1970

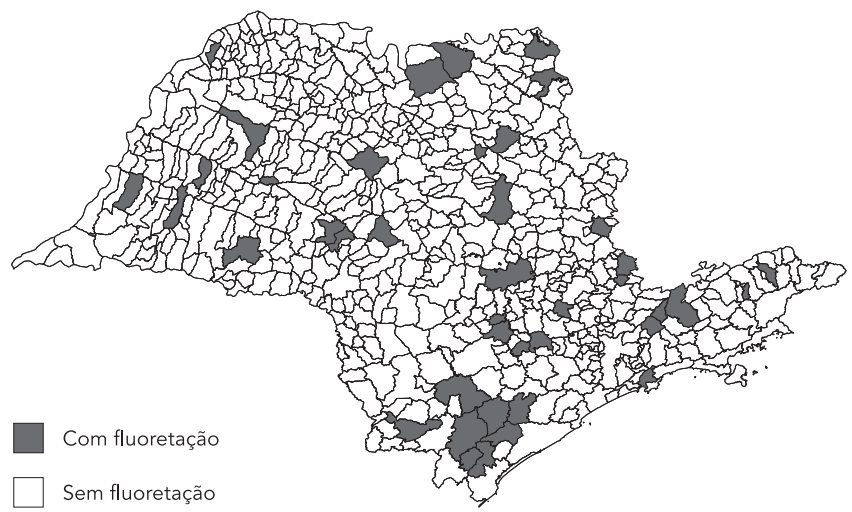

2e) Anos 1990

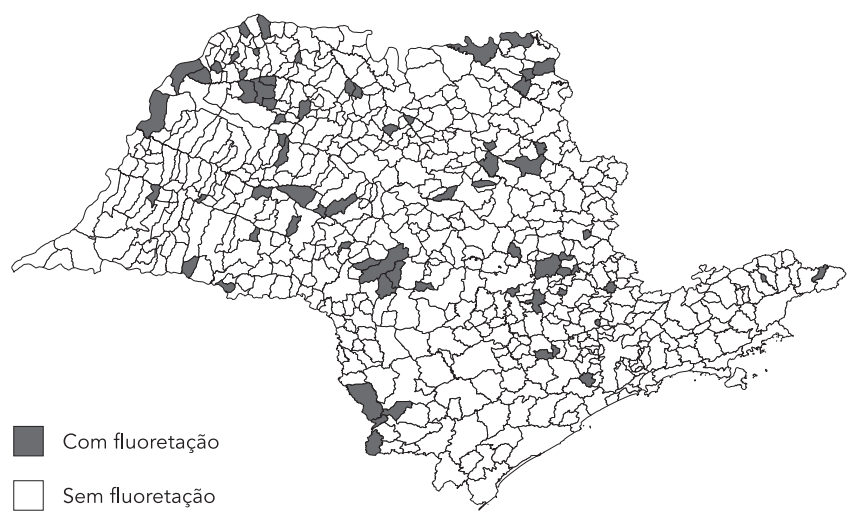

2b) Anos 1960

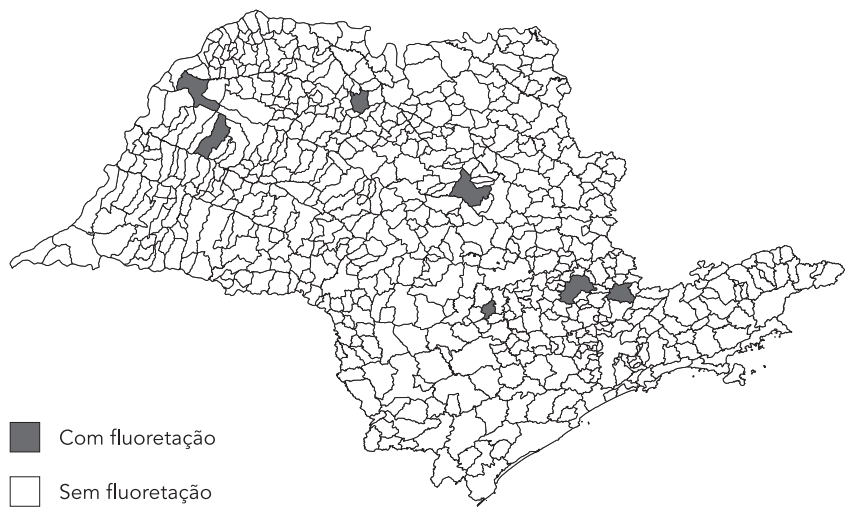

2d) Anos 1980

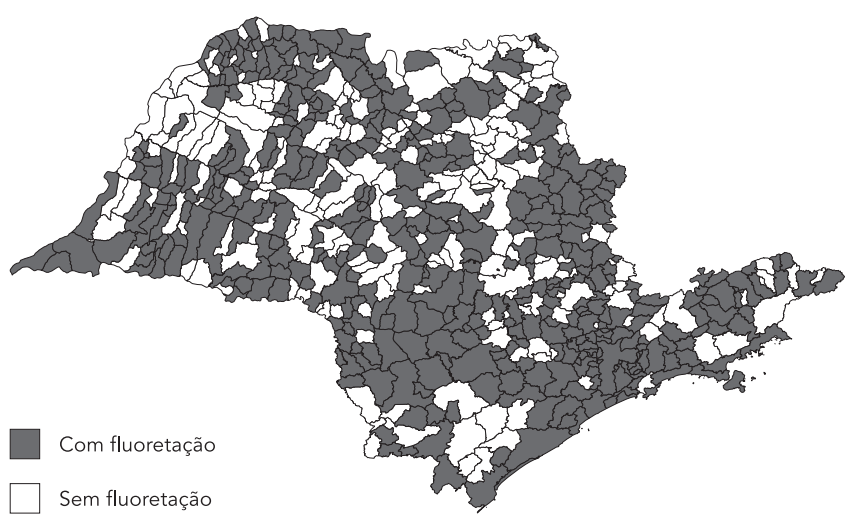

2f) Anos 2000

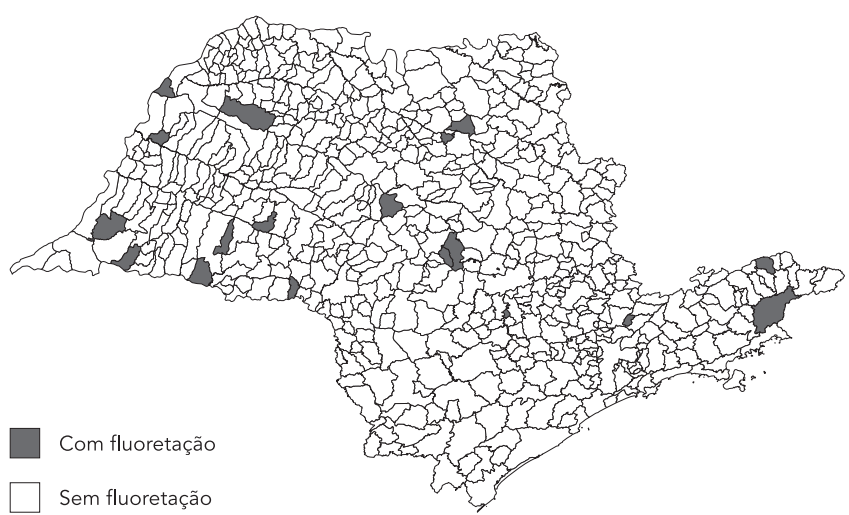


Proporção da população abastecida por rede de água com acesso à água fluoretada, no Estado de São Paulo, Brasil, no período de 1972 a 2009.

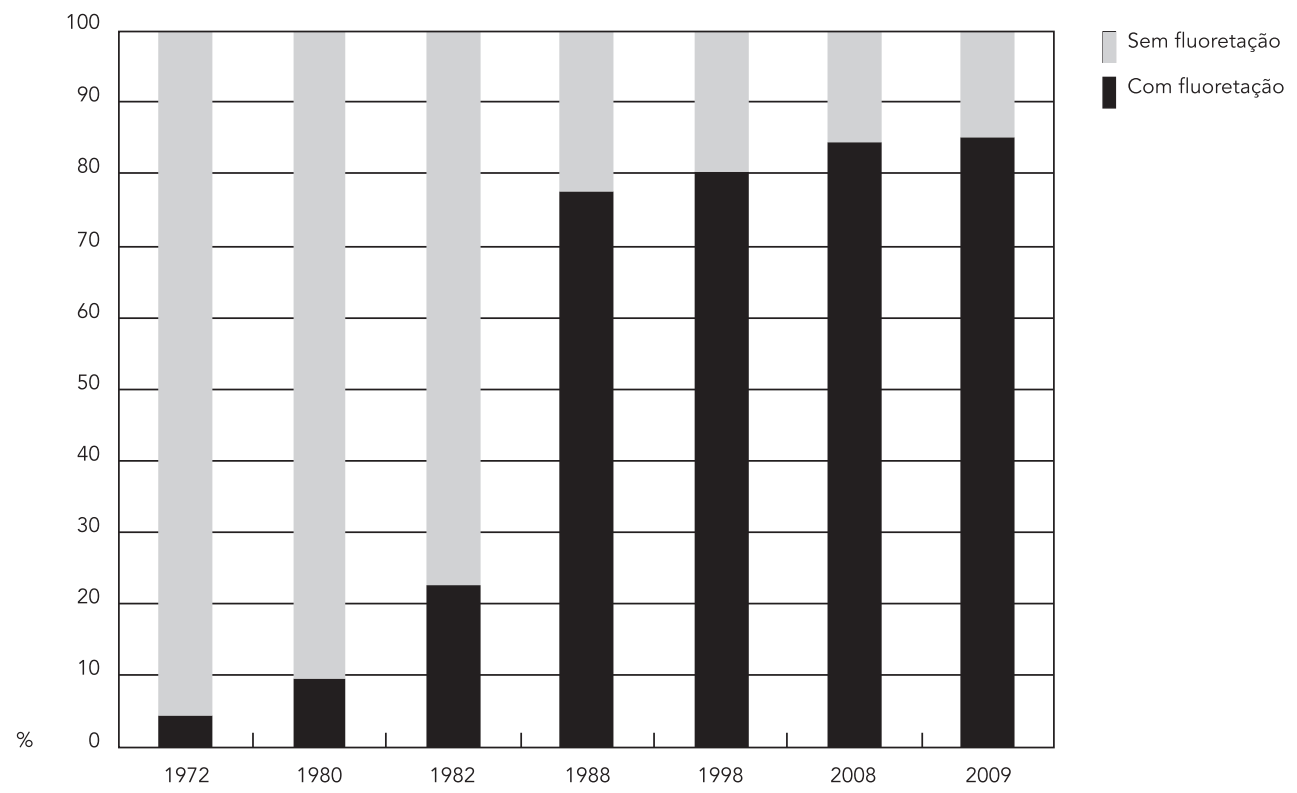

Fonte: Buendia 20, Grinplastch 39, Batalha et al. 40, Grupo Estadual de Controle e Fluoretação das Águas 41, Silva 42, Programa de Vigilância da Qualidade da Água para Consumo Humano do Estado de São Paulo 43,44 e Fundação Seade (http://www.seade.gov.br, acessado em 03/Abr/2010).

representam o número de municípios que iniciaram a fluoretação até o fim dos decênios 1980, 1990 e 2000, e os mapas de cobertura nos respectivos anos.

No período compreendido entre 1956 e 1988, 473 municípios iniciaram a fluoretação. Desses, $308(65,1 \%)$ estavam com a fluoretação implantada nas cinco averiguações adotadas para esta análise (1988, 1998, 2001, 2008 e 2009). A interrupção da medida, ao menos uma vez no período sob estudo, ocorreu em 165 municípios (34,8\%).

\section{Discussão}

Saúde é direito de todos e dever do Estado, afirma a Constituição brasileira, tendo a universalidade do acesso às ações e aos serviços como um dos princípios que rege o sistema de saúde do país. Nesse contexto, as Diretrizes da Política Nacional de Saúde Bucal 14, apresentadas em 2004 pelo Ministério da Saúde e aprovadas pelo Conselho Nacional de Saúde e outras instâncias de decisão do SUS, são entendidas como a refe- rência política, científica e técnica para o processo de reorientação das concepções e práticas no campo da saúde bucal. Nesse documento, o acesso à água tratada e fluoretada é reafirmado como fundamental para a saúde da população.

São Paulo, situado na Região Sudeste, é um dos estados mais desenvolvidos do país no que se refere ao acesso à água fluoretada. Os dados analisados neste estudo indicam que chegava a 546 o número de municípios que, em 2009, fluoretavam suas águas. Até o final dos anos 1960, menos de $2 \%$ dos municípios paulistas eram fluoretados. Em meados dos anos 1980, apenas um quarto dos municípios contavam com a medida. Ao final dos anos 1980, cerca de $70 \%$ dos municípios estavam sendo beneficiados, incluindo a capital. Essa ampliação correspondeu a um expressivo aumento (45\%) em cinco anos. Em termos populacionais, a cobertura cresceu de aproximadamente $0,7 \%$ para 85,1\%, de 1956 a 2009. O acentuado aumento do percentual de cobertura de 1982 para 1988, de $22,7 \%$ para $77,5 \%$ da população, deveu-se, em grande parte, ao início, em 1985, da fluoretação na capital e 


\section{Figura 4}

Municípios do Estado de São Paulo, Brasil, com fluoretação iniciada e cobertura nos anos 1980, 1990 e 2000.

4a) Com fluoretação iniciada até 1989

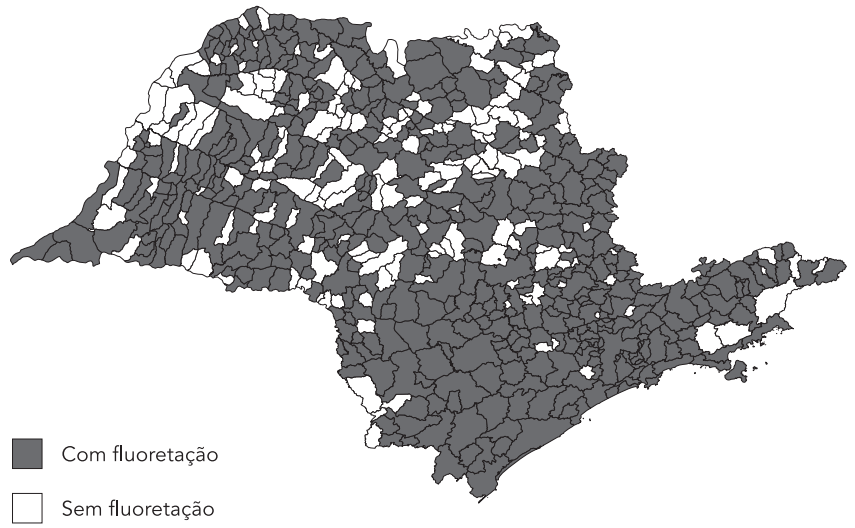

4c) Com fluoretação iniciada até 1999

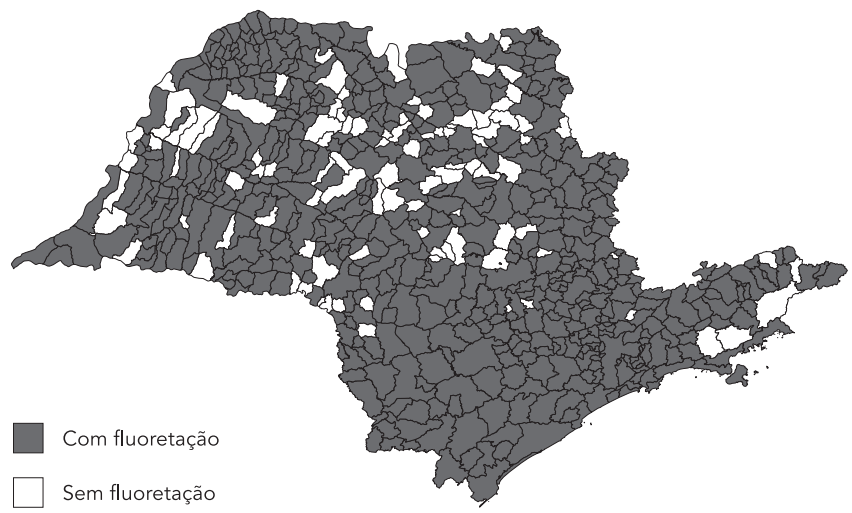

4e) Com fluoretação iniciada até 2009

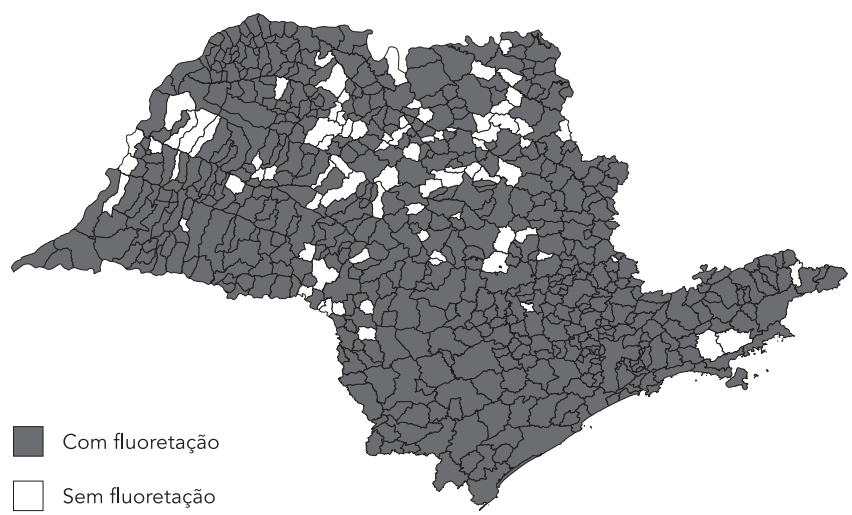

4b) Situação da fluoretação em 1989

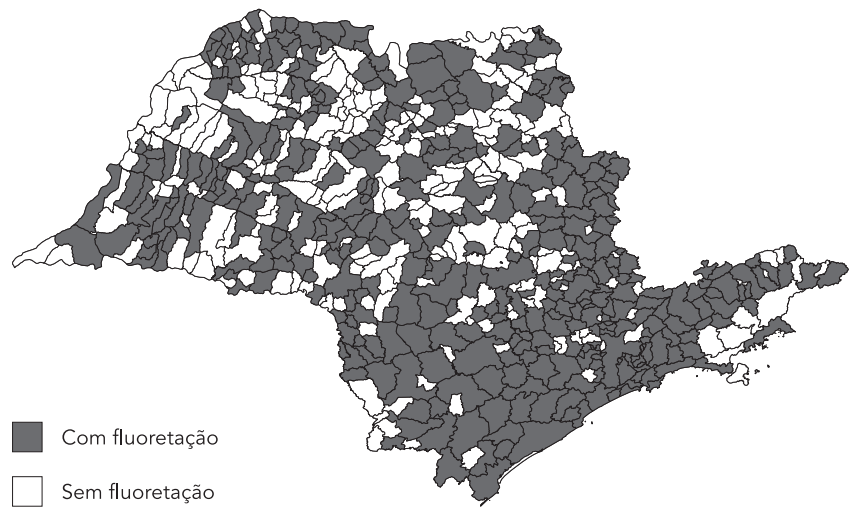

4d) Situação da fluoretação em 1999

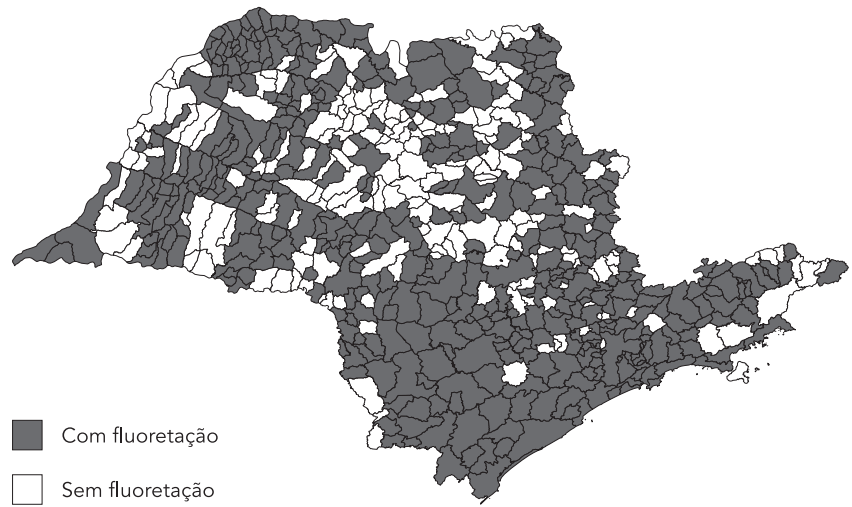

4f) Situação da fluoretação em 2009

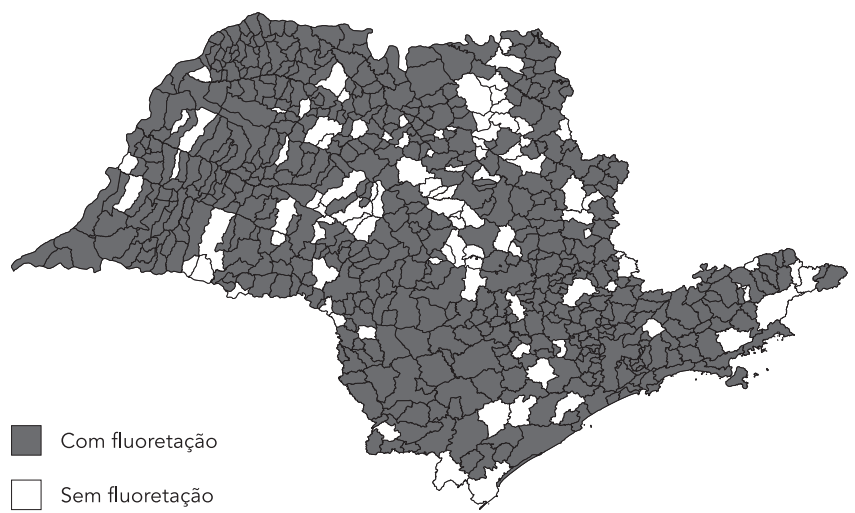


na região metropolitana de São Paulo, onde se concentra um grande contingente populacional (quase $50 \%$ da população do estado, em 2009).

A ampliação e consolidação da fluoretação das águas, e a consequente manutenção de altos níveis de acesso à medida no Estado de São Paulo, correlaciona-se negativamente com a prevalência e severidade da cárie dentária nesse território. A literatura sobre o assunto indica que, quanto maior o acesso à água fluoretada, menores a prevalência e a magnitude da doença, em termos populacionais 10,22 .

Com efeito, estudos realizados em municípios paulistas mostram que, no período sob análise, houve declínio na prevalência de cárie. Os valores indicam que o declínio variou desde $57 \%$ para a dentição permanente e $49 \%$ para a dentição decídua em 14 anos de implantação da fluoretação em Campinas, até $89 \%$ de redução em crianças de 3 a 5 anos de idade, com 5 ou mais dentes cariados, em Barretos, após dez anos de implantação da medida. Nessa mesma cidade, um estudo analisando os resultados de dezesseis anos de acesso à água fluoretada indicou que houve 59\% de aumento de jovens de 15 a 19 anos sem experiência de cárie. Outras cidades paulistas registraram valores no mesmo sentido, como Piracicaba, com redução de $79 \%$ do percentual de cárie dentária entre escolares de 6 a 12 anos, após 25 anos de implementação da medida 23,24,25.

Além de se manter efetiva na prevenção da cárie dentária, a água fluoretada vem sendo associada fortemente à diminuição das perdas dentárias ocasionadas por cárie em adolescentes e adultos 26,27 .

Segundo o Ministério da Saúde, “aproximadamente 100 milhões” de brasileiros estariam sendo beneficiados pela agregação de flúor às águas em 2007 28. Admitindo-se essa estimativa, cerca de $52 \%$ da população teriam acesso à água fluoretada no Brasil, com um expressivo aumento de 10 pontos na porcentagem (42\%) registrada para o ano de 1996 (Figura 1). Considerando-se, conforme apresentado neste estudo, que já no ano 2000, no Estado de São Paulo a água de abastecimento público fluoretada chegava a $85 \%$ dos municípios, constata-se que esta condição situa o estado bem acima da média brasileira 17 .

Ao se analisar o acesso à fluoretação no Estado de São Paulo e no Brasil, pode-se inferir que a cobertura da medida atingiu seu maior índice de crescimento nos anos 1980, tanto em nível nacional como estadual, sobretudo após a sua regulamentação em 1974. Dos anos 1970 aos 1980, em nível nacional, triplicou o percentual de cobertura, enquanto no Estado de São Paulo este incremento foi de duas vezes. Já dos anos
1980 aos 1990, em todo o território brasileiro, houve um incremento de 4,5 vezes, enquanto no estado observou-se um aumento de oito vezes. Esse aumento coincidiu com a fase em que, no Brasil, a medida foi fortemente incentivada com recursos federais para expansão dos sistemas de fluoretação 29 .

Sobre o crescimento e a distribuição espacial do período de implantação da fluoretação observa-se na Figura 2 que, até os anos 1980, houve um aumento substancial em todas as regiões do estado, sobretudo nos municípios das regiões metropolitana, central e sul. Nos anos 1990 e 2000, o mapa da evolução pouco se alterou, com predominância de municípios com ausência da medida nas regiões geograficamente localizadas ao norte-central e noroeste do estado.

Cabe assinalar que todos os municípios paulistas têm acesso à rede de tratamento de água. No entanto, 70 municípios nunca iniciaram o processo de fluoretação em seus sistemas de tratamento, até o ano de 2009. As regiões do estado que ainda contemplam maior número de municípios sem implantação da fluoretação são as localizadas geograficamente ao norte e noroeste, com os municípios de até 50 mil habitantes concentrando $99 \%$ dos municípios sem acesso ao benefício.

Esses resultados denotam a persistência de dificuldades para os municípios de pequeno porte, relacionados ao aspecto operacional e aos custos iniciais para implantação. Sabe-se que os municípios de pequeno porte têm maior dificuldade em se adequar às metas de universalização dos serviços de abastecimento de água. Segundo a Pesquisa Nacional de Saneamento Básico (PNSB) de 2000 17, 73\% dos municípios brasileiros situavam-se na faixa populacional até $20 \mathrm{mil}$ habitantes. Nesse estrato, apenas $46 \%$ dos domicílios ocupados contavam com abastecimento de água geral. Por outro lado, nos municípios com mais de 300 mil habitantes esse percentual subia para $75 \%$. De acordo com a PNSB, isso se explica pela maior demanda nos municípios de maior porte populacional, situados em áreas com maior desenvolvimento socioeconômico e maiores investimentos, tanto do setor público quanto do setor privado.

A fluoretação, por ser uma medida que depende da rede de distribuição de água e também do tratamento adequado da água, torna-se dependente diretamente dessas demandas, acompanhando, portanto, essa baixa cobertura naqueles municípios de menor porte populacional. Entende-se por essa situação que municípios de menor porte demográfico possuem menores investimentos, menos acesso à água tratada e de boa qualidade, incluindo a fluoretação. Tais 
municípios expõem, portanto, suas populações à desigualdade de condições e de acesso aos níveis adequados de saúde. Assim, populações que apresentam condições socioeconômicas desfavoráveis e que, por isto, são as que mais necessitam de intervenções de saneamento básico (como o tratamento adequado de água), acabam sendo excluídas ou recebem tardiamente o benefício. O fato de ações e medidas de saúde alcançarem primeiro as populações de maior nível de desenvolvimento, e não o contrário, é fenômeno recorrente, conhecido 30,31,32 e, porque trata-se de uma forma de injustiça social, deve constituir uma preocupação permanente dos tomadores de decisão relacionada com as políticas públicas de interesse da saúde, como é o caso da fluoretação das águas.

Contudo, é preciso cautela na interpretação desse "atraso" no acesso à fluoretação e, sobretudo, do que a fluoretação significa para essas populações. Narvai 11 argumenta ser falacioso o argumento de que os que mais precisam não se beneficiam porque não têm acesso à água, que beneficiaria principalmente os que moram nas regiões centrais das cidades. Também, a experiência brasileira mostra que, na prática, dá-se exatamente o contrário: o benefício é proporcionalmente maior justamente nos segmentos que não têm acesso a outros fatores de proteção - ou esse acesso é marcadamente restrito. Portanto, é justamente nos que mais precisam que o benefício tem mais força ${ }^{32}$. Além disso, a fluoretação das águas, ainda que tardia para as populações de determinados territórios, apresenta um enorme potencial de universalização e, ademais, contribui para que as pessoas tenham acesso à água tratada, talvez a mais importante ação de saúde pública. Por isso, é socialmente injusto não realizá-la ou interrompê-la.

Em relação ao percentual da população abastecida por sistema de tratamento que recebe água fluoretada, este estudo apurou que, em 2009, 93,5\% foram beneficiados. A Figura 3 mostra essa evolução, apresentando em 1980 um indicador de cobertura de quase $12 \%$, aumentando para quase $85 \%$ em 1988 e atingindo $89 \%$ ao final dos anos 90 .

A esse respeito, pode-se comparar os dados obtidos neste trabalho com os encontrados pelo CDC, para os Estados Unidos. O CDC mantém um sistema de informação aberto, que tem, entre outros objetivos, servir como base de dados para relatórios nacionais sobre cobertura da população que recebe água fluoretada dos sistemas públicos de abastecimento de água. No Brasil, o SISAGUA 18, desenvolvido pelo Ministério da Saúde, tem como objetivo produzir, analisar e disseminar dados sobre a qualidade da água para consumo humano, de acordo com os padrões de potabilidade, tendo o nível de fluoreto como um dos indicadores contemplados para avaliação e monitoramento da qualidade da água. No entanto, neste estudo, tal sistema foi utilizado apenas de modo eventual, e ainda assim parcial, como uma das fontes para confirmação de um ou outro dado, uma vez que se trata de base de dados insuficiente para abordagens exaustivas e, portanto, em profundidade, da cobertura e acesso à água fluoretada.

Sobre a interrupção da medida, em 1989, 16\% dos municípios, por algum motivo, deixaram de fluoretar suas águas. A Figura 4 mostra que, em 1999, essa situação ocorria em 96 municípios (18\%), e em 2009, em 17 (3\%).

Saliba et al. 33 também encontraram $17 \%$ de municípios que interromperam a medida ao estudar 40 municípios da região noroeste do Estado de São Paulo, no ano de 2005, e para estes municípios os motivos alegados foram problemas nas bombas dosadoras de flúor e contenção de despesas. Segundo Narvai et al. 34, é de conhecimento dos envolvidos com a fluoretação das águas que, frente a dificuldades econômicas ou necessidade de reduzir custos, esta medida é a primeira a ser cogitada para suspensão.

Dados publicados em 2008 nos Estados Unidos, mostravam que a cobertura da fluoretação da água pelos sistemas de abastecimento naquele país evoluiu de $62,1 \%$ em 1992 para 65,0\% em 2000 , e para $69,2 \%$ em 2006, sendo que a meta estabelecida para o país até 2010 foi de $75 \%$ da população sendo abastecida por sistemas de água com fluoretação 35 . Conforme relatado neste estudo, o índice de cobertura da fluoretação pelos sistemas de tratamento de água do Estado de São Paulo nos anos 1990 foi de 88,5\%, atingindo em 2009, 93,5\%. Embora a realidade daquele país, em termos operacionais, metodologias e condições em que os dados são disponibilizados seja bem diferente da realidade brasileira, os resultados indicam que o Estado de São Paulo, em 2009, tinha uma cobertura de sistemas fluoretados com níveis acima da média nacional norteamericana.

Não obstante esse índice de acesso de 93,5\% da população seja bastante expressivo, cabe enfatizar que havia, naquele ano, cerca de 2,5 milhões de habitantes abastecidos por água tratada e ainda não fluoretada. Esse contingente correspondia ao equivalente a um quarto da população do Município de São Paulo.

Identificar os fatores que dificultam a expansão do acesso às populações desses territórios e adotar as estratégias adequadas para superálas é, portanto, o desafio que se impõe às autoridades públicas e se constitui prioridade den- 
tro do contexto da universalização dessa medida. Embora a responsabilidade pela conquista e manutenção da fluoretação das águas seja da sociedade como um todo, a responsabilidade legal e ética por sua execução é das autoridades governamentais, cabendo-lhes assegurar a todos os cidadãos o exercício desse direito. É nesse sentido que deve ser vista a proposta aprovada na $3 \underline{a}$ Conferência Nacional de Saúde Bucal 36, pedindo a garantia do "cumprimento da Lei 6.050/74, que prevê a fluoretação e o tratamento das águas de abastecimento público".

\section{Considerações finais}

Os resultados deste estudo mostram que a cobertura da fluoretação da água de abastecimento público no Estado de São Paulo evoluiu consideravelmente desde o início da implantação da medida até 2009. A expansão foi lenta, registra-

\section{Resumo}

Ter acesso à água fluoretada é um reconhecido fator de proteção contra a cárie dentária. No Brasil, a fluoretação da água de abastecimento público tornou-se obrigatória por lei em 1974, seguindo-se a esta regulamentação acentuada expansão da cobertura, sobretudo nas regiões de maior desenvolvimento socioeconômico. A ampliação dessa cobertura em todo o país é uma das prioridades da política nacional de saúde bucal. Neste artigo, sistematizam-se informações sobre a implantação e expansão da fluoretação no Estado de São Paulo, no período de 1956 a 2009, utilizando-se dados secundários obtidos em relatórios técnicos, documentos oficiais e no sistema SISAGUA. Em 2009, a cobertura se estendia por 546 (84,7\%) dos 645 municípios paulistas, chegando a $85,1 \%$ da população total e a 93,5\% da população com acesso à rede de distribuição de água. Tais resultados indicam que a medida está consolidada como parte da política estadual de saúde. No entanto, persiste o desafio de implantar e manter a fluoretação em 99 municípios, beneficiando cerca de 6,2 milhões de habitantes excluídos do benefício.

Fluoretação; Abastecimento de Água; Saúde Bucal ram-se interrupções em vários municípios (mais de um terço, até o final dos anos 1980), porém, ao longo de mais de meio século de implantação, a medida foi se consolidando como parte da política estadual de saúde.

Contudo, sua universalização não foi alcançada, restando segmentos da população, residentes principalmente nos municípios de pequeno porte, excluídos do benefício. Persiste, no final da primeira década do século XXI, o desafio de implantar e, sobretudo manter, a fluoretação da água em 99 municípios, dos quais 70 nunca chegaram a iniciar a medida e, deste modo, beneficiar os cerca de 6,2 milhões de paulistas sem acesso à água fluoretada. Mesmo que esse contingente populacional se localize em municípios de pequeno porte demográfico, suas populações têm direito a esse benefício e cabe às autoridades públicas assegurar esse direito e, desse modo, contribuir para a diminuição das desigualdades em saúde.

\section{Colaboradores}

R. X. Alves contribuiu na concepção e desenho do estudo, análise e interpretação dos dados, redação do artigo e revisão final após a contribuição dos coautores. G. F. Fernandes, M. T. P. Razzolini, P. Frazão e R. A. A. Marques colaboraram na análise e interpretação dos dados, revisão crítica do conteúdo intelectual e aprovação final da versão para publicação. P. C. Narvai contribuiu na concepção e desenho, análise e interpretação dos dados, revisão crítica do conteúdo intelectual, revisão e aprovação final da versão para publicação.

\section{Agradecimentos}

À Coordenação de Aperfeiçoamento de Pessoal de Nível Superior (CAPES) pela bolsa de estudos concedida à Renata Ximenez Alves. À Secretaria de Vigilância em Saúde, Ministério da Saúde (convênio 1978/2008CECOL/USP). 


\section{Referências}

1. Narvai PC, Frazão P, Roncalli AG, Antunes JL. Cárie dentária no Brasil: declínio, polarização, iniqüidade e exclusão social. Rev Panam Salud Pública 2006; 19:385-93.

2. Pinto VG. Epidemiologia das doenças bucais no Brasil. In: Kriger L, coordenador. ABOPREV: promoção de saúde bucal. 2a Ed. São Paulo: Editora Artes Médicas; 1999. p. 29-41.

3. Cury JA. Uso do flúor e controle da cárie como doença. In: Baratieri LN, organizador. Odontologia restauradora - fundamentos e possibilidades. São Paulo: Santos/Quintessence; 2006. p. 33-68.

4. Centers for Disease Control and Prevention. Engineering and administrative recommendations for water fluoridation, 1995. MMWR Recomm Rep 1995; 44(RR-13):1-40.

5. World Health Organization. Fluorides and oral health. Report of WHO expert committee and oral health status and fluoride use. Geneva: World Health Organization; 1994. (WHO Technical Report Series, 846).

6. World Health Organization. Sixtieth World Health Assembly; 2007. Oral health: action plan for promotion and integrated disease prevention. http:// apps.who.int/gb/ebwha/pdf_files/WHASSA_ WHA60-Rec1/E/reso-60-en.pdf (acessado em 01/ Abr/2010).

7. Centers for Disease Control and Prevention. Ten great public health achievements: United States, 1900-1999. MMWR Morb Mortal Wkly Rep 1999; 48:241-3.

8. Centers for Disease Control and Prevention. Achievements in public health, 1900-1999: fluoridation of drinking water to prevent dental caries. MMWR Morb Mortal Wkly Rep 1999; 48:933-40.

9. Riley JC, Lennon MA, Ellwood RP. The effect of water fluoridation and social inequalities on dental caries in 5-year-old children. Int J Epidemiol 1999; 28:300-5.

10. Jones CM, Worthington H. Water fluoridation, poverty and tooth decay in 12-year-old children. J Dent 2000; 38:389-93.

11. Narvai PC. Cárie dentária e flúor: uma relação do século XX. Ciênc Saúde Coletiva 2000; 5:381-92.

12. Brasil. Lei Federal n 6.050 de 24 de maio de 1974. Dispõe sobre a fluoretação da água em sistemas de abastecimento quando existir estação de tratamento. http://dtr2004.saude.gov.br/dab/docs/ legislacao/lei6050_24_05_74.pdf (acessado em 05/ Dez/2008).

13. Brasil. Decreto $\mathrm{n}^{\circ}$. 76.872 de 22 de dezembro de 1975. Regulamenta a Lei n. 6.050, de 24 de maio de 1974, que dispõe sobre a fluoretação da água em sistemas públicos de abastecimento. http://dtr 2004.saude.gov.br/dab/docs/legislacao/decreto 76842_22_12_75.pdf (acessado em 05/Dez/2008).

14. Secretaria de Atenção à Saúde, Ministério da Saúde. Diretrizes da Política Nacional de Saúde Bucal. http://bvsms.saude.gov.br/bvs/publicacoes/poli tica_nacional_brasil_sorridente.pdf (acessado em 07/Fev/2010).
15. Secretaria de Atenção à Saúde, Ministério da Saúde. Projeto SB Brasil 2003: condições de saúde bucal da população brasileira 2002-2003: resultados principais. http://dtr2004.saude.gov.br/dab/cnsb/ publicacoes.php (acessado em 04/Jan/2009).

16. Buendia OC. Fluoretação de águas de abastecimento público no Brasil: atualização. Rev Assoc Paul Cir Dent 1984; 38:138-58.

17. Instituto Brasileiro de Geografia e Estatística. Pesquisa Nacional de Saneamento Básico 2000. http:// www.ibge.gov.br/home/estatistica/populacao/con dicaodevida/pnsb/pnsb.pdf (acessado em 03/ Dez/2008).

18. Secretaria deVigilância em Saúde, Ministério da Saúde. Sistema de Informação de Vigilância da Qualidade da Água para Consumo Humano (SISAGUA). http://www.saude.gov.br/sisagua (acessado em 10/ Abr/2010).

19. São Paulo. Resolução SS-250/95. Define teores de concentração do íon fluoreto nas águas para consumo humano, fornecidas por sistemas públicos de abastecimento. Diário Oficial do Estado de São Paulo 1995; 15 ago.

20. Buendia OC. Situação atual da fluoretação de águas de abastecimento público no Estado de São Paulo, Brasil. Rev Saúde Pública 1983; 17:226-32.

21. Calvo MCM. Situação da fluoretação de águas de abastecimento público no Estado de São Paulo [Dissertação de Mestrado]. São Paulo: Faculdade de Saúde Pública, Universidade de São Paulo; 1997.

22. Peres MA, Antunes JLF, Peres KG. Is water fluoridation effective in reducing inequalities in dental caries distribution in developing countries? Recent findings from Brazil. Soz Praventiv Med 2006; 51:302-10.

23. Viegas Y, Viegas AR. Prevalência de cárie dental na Cidade de Campinas, SP, Brasil, depois de quatorze anos de fluoração da água de abastecimento público. Rev Assoc Paul Cir Dent 1985; 39:372-82.

24. Viegas Y, Viegas AR. Prevalência de cárie dental em Barretos, SP, Brasil, após dezesseis anos de fluoretação da água de abastecimento público. Rev Saúde Pública 1988; 22:25-35.

25. Basting RT, Pereira AC, Meneghim MC. Avaliação da prevalência de cárie dentária em escolares do Município de Piracicaba, SP, Brasil, após 25 anos de fluoretação das águas de abastecimento público. Rev Odontol Univ São Paulo 1997; 11:287-92.

26. Frazão P, Antunes JLF, Narvai PC. Perda dentária precoce em adultos de 35 a 44 anos de idade: Estado de São Paulo, Brasil, 1998. Rev Bras Epidemiol 2003; 6:49-57.

27. Barbato PR, Peres MA. Perdas dentárias em adolescentes brasileiros e fatores associados: estudo de base populacional. Rev Saúde Pública 2009; 43:13-25.

28. Narvai PC, Frazão P. Saúde bucal no Brasil: muito além do céu da boca. Rio de Janeiro: Editora Fiocruz; 2008.

29. Pinto VG. Revisão sobre o uso e segurança do flúor. RGO (Porto Alegre) 1993; 41:263-6. 
30. Peres MA, Fernandes LS, Peres KG. Inequality of water fluoridation in Southern Brazil - the inverse equity hypothesis revisited. Soc Sci Med 2004; 58:1181-9.

31. Gabardo MCL, da Silva WJ, Moysés ST, Moysés SM. Water fluoridation as a marker for sociodental inequalities. Community Dent Oral Epidemiol 2008; 36:103-7.

32. Antunes JLF, Narvai PC. Políticas de saúde bucal no Brasil e seu impacto sobre as desigualdades em saúde. Rev Saúde Pública 2010; 44:360-5.

33. Saliba NA, Moimaz SAS, Barbosa TF, Casotti CA. Análise do processo de fluoretação no Noroeste Paulista sob a ótica do coordenador de Saúde Bucal. Rev Odontol Univ Cid São Paulo (Online) 2007; 19:293-9.

34. Narvai PC, Frazão P, Fernandez RAC. Fluoretação da água e democracia. Saneas 2004; 2:29-33.

35. Centers for Disease Control and Prevention. Populations receiving optimally fluoridated public drinking water - United States, 1992-2006. MMWR Morb Mortal Wkly Rep 2008; 57:737-41.

36. Ministério da Saúde. Relatório final da 3a Conferência Nacional de Saúde Bucal. Brasília: Ministério da Saúde; 2005.

37. Narvai PC. Vigilância sanitária da fluoretação das águas de abastecimento público no Município de São Paulo, no período 1990-1999 [Tese de LivreDocência]. São Paulo: Faculdade de Saúde Pública, Universidade de São Paulo; 2001.

38. Organización Panamericana de la Salud. Estado de la fluoruración de las aguas en las Américas. Washington DC: Organización Panamericana de la Salud/Organización Mundial de la Salud; 1969.

39. Grinplastch BS. Fluoretação de águas no Brasil. Bol Oficina Sanit Panam 1974; 76:321-30.
40. Batalha BHL, Viegas AR, Gorchev HG, Pace G. Binômio fluoretação da água e cárie dentária. In: Seminário sobre fluoretação Pró Limp 4. São Paulo: SAENSA/CETESB/SOMA; 1984. p. 14-5.

41. Grupo Estadual de Controle de Fluoretação das Águas. Relatório do levantamento realizado pelo GECOF-SP sobre fluoretação de águas de abastecimento público no Estado de São Paulo. São Paulo: Grupo Estadual de Controle de Fluoretação das Águas; 1988.

42. Silva PR. Influência dos aspectos socioeconômicos e ambientais na prevalência da cárie dentária e sua distribuição geográfica no Estado de São Paulo em 1998 [Tese de Doutorado]. São Paulo: Faculdade de Saúde Pública, Universidade de São Paulo; 2005.

43. Programa de Vigilância da Qualidade da Água para Consumo Humano do Estado de São Paulo. Relatório de janeiro a dezembro de 2008 sobre fluoreto nos sistemas de abastecimento de água dos municípios do Estado de São Paulo [Relatório Técnico]. São Paulo: Centro de Vigilância Sanitária, Secretaria de Estado da Saúde; 2010.

44. Programa de Vigilância da Qualidade da Água para Consumo Humano do Estado de São Paulo. Relatório de janeiro a dezembro de 2009 sobre fluoreto nos sistemas de abastecimento de água dos municípios do Estado de São Paulo [Relatório Técnico]. São Paulo: Centro de Vigilância Sanitária, Secretaria de Estado da Saúde; 2010.

Recebido em 07/Jan/2011

Versão final reapresentada em 16/Jun/2011

Aprovado em 19/Jul/2011 